\title{
Racial/Ethnic Variations in Violence Against Women: Urban, Suburban, and Rural Differences
}

\author{
WALTER S. DEKESEREDY \\ Professor \\ Faculty of Social Science and Humanities \\ University of Ontario Institute of Technology \\ Room 304 Bordessa Hall \\ Oshawa, Ontario Canada \\ L1H 7K4 \\ walter.dekeseredy@uoit.ca \\ Molly DRAGIEWICZ \\ Associate Professor \\ Faculty of Social Science and Humanities \\ University of Ontario Institute of Technology \\ Bordessa Hall \\ Oshawa, Ontario Canada \\ L1H 7K4 \\ Molly.dragiewicz@uoit.ca \\ CALLIE MARIE RENNISON \\ Associate Professor \\ School of Public Affairs \\ University of Colorado Denver \\ P.O. Box 173364 - Campus Box 142 \\ Denver, Colorado USA 80217 \\ Callie.Rennison@ucdenver.edu
}

Contact author - Walter DeKeseredy: walter.dekeseredy@uoit.ca;

\begin{abstract}
A large literature shows that violence against women in intimate relationships varies across racial/ethnic groups. However, it is unclear whether such variations differ across urban, suburban, and rural areas. The main objective of this article is to examine this issue using 1992 to 2009 National Crime Victimization Survey data. We also test the hypothesis that racial/ethnic minority women living in rural areas are more likely to be assaulted by their current and former intimate partners than are their urban and suburban counterparts. Contrary to expectations, results indicated virtually no differences in the rates at which urban, suburban, and rural racial/ethnic minority females were victims of intimate violence. The results indicate the great need of additional research into this important topic.
\end{abstract}

\section{Keywords: Violence Against Women, Race/Ethnicity, Rural, Urban, National Crime Victimization Survey (NCVS).}


Racial/Ethnic Variations in Violence Against Women: Urban, Suburban, and Rural Differences DeKeseredy, Dragiewicz, and Rennison

\section{Introduction}

Empirical and theoretical work on violence against women in dating, marriage, cohabitation, and during or after separation/divorce has grown exponentially over the past 40 years. In addition, social scientific work on this social problem has branched into new substantive and geographic areas (Renzetti, Edleson, \& Kennedy Bergen 2011). For example, there is now a burgeoning literature on violence against women "at the margins" (Sokoloff 2005), including interdisciplinary analyses of various types of woman abuse in rural parts of North America and in communities of color (e.g., DeKeseredy \& Schwartz 2009; Potter 2008; Rennison, DeKeseredy, \& Dragiewicz in press a). Still, much of the extant research underrepresents many racial and ethnic minority groups (Perilla, Lippy, Rosales, \& Serrata 2011), especially those living in rural areas. Further, it is unclear whether ethnic/racial variations in violence against women in intimate relationships differ across urban, suburban, and rural communities. This article uses aggregate 1992 to 2009 National Crime Victimization Survey data (NCVS) to help fill this research gap.

For several reasons, such as socioeconomic status and isolation (Perilla et al. 2011), members of some racial/ethnic groups (e.g., African-American, American Indian/Alaska Native and mixed race) experience higher rates of intimate violence against women than do other racial/ethnic groups (Basile \& Black 2011; Tjaden \& Thoennes 2000). We hypothesize, however, that racial/ethnic minority women living in rural locations may be at even higher risk of being beaten, sexually assaulted, and experiencing other types of "intimate intrusions" (Stanko 1985). This assumption is informed by an emerging body of research on the heightened risk of woman abuse in rural settings. For instance, roughly 1 in 4 rural women are assaulted by male partners at some point in their lives (Breiding, Ziembroski, \& Black 2009). In addition to experiencing racism, suspicion and marginality in rural areas (Cloke 2004), rural racial/ethnic minority women are more vulnerable to experiencing intimate violence because of the following problems identified by previous rural woman abuse studies:

- Geographic and social isolation, poverty, barriers to service and fewer social support resources (Logan, Cole, \& Walker 2006; Logan, Evans, Stevenson, \& Jordan 2005; Websdale \& Johnson 2005).

- Inadequate (if any) public transportation, which helps trap women in violent relationships (Lewis 2003).

- A powerful "good ol' boys network" consisting of patriarchal criminal justice officials and some abusive men (Websdale 1998).

- Community norms prohibiting women from publicly talking about their experiences and seeking social support (Brownridge 2009; DeKeseredy \& Schwartz 2008).

- Patriarchal male peer support (DeKeseredy \& Schwartz 2009), which is "attachments to male peers and the resources they provide that encourage and legitimate woman abuse" (DeKeseredy 1990, 130). 
- Rural women are less likely to be insured than their urban and suburban counterparts (Mueller \& MacKiney 2006; Patterson 2006), which restricts their access to physical and mental health care services (Basile \& Black 2011).

Of course some of these problems also exist in urban areas. Indeed, it is well known that many urban police officers ignore the plight of battered women and sexual assault survivors (Meloy \& Miller 2011). While there is a system of social practices that oppresses rural and urban women alike, it operates differently in rural areas (DeKeseredy \& Schwartz 2009). Furthermore, given the nature of rural racism (Chakraborti \& Garland 2004), the "battle cries" of abused racial/ethnic minority women are more likely to be unheard than those of white women (Potter 2008). Certainly, racial and ethnic privilege are strongly linked to how services are allocated and delivered (Richie 2005).

\section{Data and Methods}

\section{Data}

Sponsored by the U.S. Bureau of Justice Statistics, the National Crime Victimization Survey (NCVS) is an ongoing, large, nationally representative survey of households and people age 12 or older in the U.S. The data are publicly available through the National Archive of Criminal Justice Data (NACJD) and are collected using a rotating, stratified, multistage cluster design (Rennison \& Rand 2007). The NCVS is fielded at a sample of housing units and group quarters in the U.S. and the District of Columbia. In each selected housing unit, all persons age 12 or older in the sampled dwelling are interviewed once every six months for a total of seven interviews. The NCVS produces data representative of the non-institutionalized U.S. population in this age range (Bachman 2000; Rennison \& Rand 2007). Interviews are conducted both in person and over the phone.

Recently, NCVS data were analyzed to determine long-term trends in violence against women and variations in urban, suburban, and rural rates of such violence in ongoing relationships and in the context of separation/divorce (Lauritsen \& Heimer 2008; Rennison et al. in press a; Rennison, DeKeseredy, \& Dragiewicz in press b). However, geographic area differences in intimate violence against women belonging to different racial/ethnic groups have not been examined. This study contributes to the expansion of research on rural gendered violence and puts race/ethnicity at the forefront of analysis, following the studies of some British and Australian rural criminologists (Chakraborti \& Garland 2004; Hogg \& Carrington 2006).

\section{Sample}

Our analysis centers on a sample of non-fatal violent assaults on women age 12 or older that occurred from 1992 to 2009. The harms included are attempted and completed rape, sexual assault, robbery, and assault (both aggravated and simple). The years examined reflect all data available following a significant series-breaking redesign implemented in 1992. ${ }^{1}$ The 1992 redesign introduced long term, rate-affecting changes to the survey (Hubble 1995; 
Racial/Ethnic Variations in Violence Against Women: Urban, Suburban, and Rural Differences DeKeseredy, Dragiewicz, and Rennison

Rennison \& Rand 2007). The changes implemented were numerous, including changes to the survey instruments (e.g., screener questions, new crimes added, improved cues), changes in protocols regarding measurement of certain victimizations (e.g., series victimizations), and cost-saving changes. The net effect of the redesign was to dramatically improve the survey's ability to measure victimization in general, as well as for several "difficult to measure" crimes, such as rape, sexual assault, and intimate violence in the number of victimizations counted by the survey, but the increases differed by type of crime (Kindermann, Lynch \& Cantor 1997; Rand, Lynch \& Cantor 1997). For instance, great increases in the number of rapes and intimate victimizations were measured. Furthermore, the redesign increased estimates of crimes not reported to the police more than it did crimes reported to the police (Kindermann, Lynch \& Cantor 1997).

Since the estimates from the redesigned survey are collected using a different screening strategy, post-redesign data are not comparable to that collected prior to 1992 (Rennison \& Rand 2007). The NCVS sample has historically been characterized by high response rates ranging from $90 \%$ to $96 \%$ for households and from $84 \%$ to $94 \%$ for individuals. On average since 1992, just shy of 100,000 households and approximately 184,000 persons were interviewed annually for the survey. The working file includes $12,159,587$ victimizations against females $(4,031$ unweighted cases).

\section{Measures}

\section{Intimate Partner}

Based on the data available, we define an intimate partner as a current or former spouse, boyfriend, or girlfriend. Intimate relationships include both heterosexual and same-sex couples. Analytically, we examine total intimate violence as well as three relationship categories: current spouse, former spouse and current/former boy/girlfriend. It is possible to identify which relationships are heterosexual and which are same-sex in the NCVS, but we did not disaggregate the analyses using this variable because of the small number of same-sex relationships. ${ }^{2}$ In addition, while the NCVS permits disaggregation of assaults by current and former spouses, it does not do so for boy/girlfriends.

\section{Geographic Area}

We compare rates of violence against current and former intimate female partners living in urban, suburban, and rural areas. These geographic areas are based on Metropolitan Areas (MA) as determined by the U.S. Office of Management and Budget (OMB). OMB categorizes geographic areas into three groups based on their relationship to an MA: central city, outside central city, and nonmetropolitan area. ${ }^{3}$ The use of this particular NCVS measure is consistent with the extant research on violence and victimization, in which geographic area plays a role (e.g., see Addington \& Rennison 2008; Duhart 2000; Lauritsen \& Heimer 2008; Rennison 2002; 2001; 2000; 1999; 1998; Rennison et al. in press a; b; c; Rennison \& Rand 2003). Following this body of research, we utilize the more common 
language of urban, suburban, and rural areas to refer to central city, outside central city, and nonmetropolitan area.

\section{Non-Lethal Violence}

This harm was operationalized by combining measures of attempted and completed rape/sexual assault, robbery, aggravated assault, and simple assault. In the NCVS, neither the victim, field representative, nor the researcher determines that a crime occurred or identifies the type of crime committed. Rather, using a variety of incident characteristics, a computer algorithm makes both of these determinations.

Standard NCVS definitions of violent victimization were employed. For example, rape is defined as forced sexual intercourse that includes psychological coercion and physical force, including heterosexual and same-sex rape, and rapes committed against males and females. Attempted rape includes verbal threats of rape. Sexual assault is distinct from rape and attempted rape in the NCVS and consists of incidents involving attacks or attempted attacks generally associated with unwanted sexual contact between victims and offenders. Sexual assaults may or may not involve force and include such behaviors as grabbing, fondling, and verbal threats.

Robbery constitutes property or money taken directly from a person by use or threat of force, with or without a weapon, and with or without injury. Aggravated assault is defined as an actual or attempted attack with a weapon, regardless of whether an injury resulted or an attack or attempted attack without a weapon when serious injury results. Finally, simple assault involves an attack without a weapon resulting in either a minor injury such as a bruise, cut, scrape, or scratch, or no injury. ${ }^{4}$

\section{Race/Ethnicity}

The NCVS measures of race/ethnicity are restricted to the following: white; black or African American; American Indian or Alaska Native (AI/AN); Hispanic; Asian or Pacific Islander (A/PI); and Other (respondents are asked to specify). Further, respondents can choose all of the categories that apply to them. For convenience, we refer to these groups as: white, black, American Indian, Asian, multiple race ${ }^{5}$ and Hispanic.

It is important to note, however, that the NCVS and similar measures used in largescale U.S. surveys, such as the National Violence Against Women Survey (Tjaden and Thoennes 2000), are subject to much criticism. For example, the above "pan-ethnic categories" are treated as homogenous groups but in reality include "diverse subpopulations that have very distinct ethnic, religious, historical, philosophical and social values that may have important roles in the dynamics" of violence against women (Perilla et al. 2011, 205). Certainly, not all black people are the same and there are differences in rates of violence among African-Americans, African-Caribbeans and Africans. The same can be said of violence among other ethnic groups, such as those designated as "American Indian/Alaska Native" (Aldarondo \& Castro-Fern\&ez 2011; Aldarondo \& Fernandez 2008). To the best of 
Racial/Ethnic Variations in Violence Against Women: Urban, Suburban, and Rural Differences DeKeseredy, Dragiewicz, and Rennison

our knowledge, the National Alcohol and Family Violence Survey is the only major U.S. survey specifically designed to overcome or minimize these limitations and hopefully other large-scale studies will follow suit (Aldarondo, Kaufman Kantor, \& Jasinski 2002; Kaufman Kantor, Jasinski, \& Aldarondo 1994).

Like any other survey, the NCVS has other limitations, including only capturing data from members of non-institutionalized housing units or group quarters. ${ }^{6}$ Despite these and other methodological limitations, such as literacy barriers, which have been extensively discussed elsewhere (see for example Aldarondo \& Castro-Fernandez 2011), the NCVS data reported here constitutes the first empirical attempt to discern racial/ethnic variations in violence against women in different U.S. geographic areas and thus help fill a significant gap in social scientific knowledge of one of the nation's most compelling social problems. The next step is to examine how much of the variation in violence against women among people of different racial/ethnic backgrounds can be explained by socio-demographic, environmental, and other factors (Perilla et al. 2011; Tjaden \& Thoennes 2000), which is beyond the scope of the research reported here.

\section{Analytic Strategy}

Contingency table analyses are used to examine variations in violence against women across racial/ethnic groups and geographic areas. Using NCVS data in contingency tables requires special attention. Not only are NCVS estimates subject to sampling error, but additional concerns exist because the data comes from a complex methodology utilizing strategies such as clustering. Thus, it is inappropriate to utilize analytic techniques that assume a simple random sample because they may underestimate the standard errors and result in incorrect inferences about statistical significance.

To account for this, all comparisons of estimates using NCVS data presented here are tested using specialized formulae created by the Census Bureau that take into account the complex NCVS sample. These tests use generalized variance function constant parameters to calculate variance estimates, standard errors and confidence intervals. These comparisons offer information on whether variations found between estimates are statistically different or equivalent. Caution is warranted when comparing victimization estimates not explicitly discussed in the findings. What may appear to be a large difference between estimates may not be statistically significant. In contrast, seemingly similar estimates may in fact be statistically different. All estimates and comparisons reported are based on data that has been weighted using the appropriate weights located on the data files. ${ }^{7}$

\section{Results}

Table 1 shows that slightly more than half $(55 \%)$ of all female victims of non-fatal intimate violence in our sample were victimized by a current/former boyfriend or girlfriend. About one-third (32\%) were victimized at the hands of a current spouse. In addition, 13\% were victimized by a former spouse. The sample of female victims was predominantly white (71\%). Racial/ethnic minority victims were 16\% black, 9\% Hispanic and $1 \%$ each of 
American Indian, Asian, and multiple race. Almost half of the sample of victims resided in suburban areas (46\%), about one-third (35\%) in urban communities, and the remaining $19 \%$ in rural neighborhoods. The average age of our sample of female victims was 30 years, and $23 \%$ of the sample lived in a household with an annual income of less than $\$ 10,000$. Fifty-six percent of the sample lives in a household with an annual household income of less than $\$ 30,000$. A slight majority of the victims experienced a simple assault (68\%). Finally, the largest percentage of our sample of female victims of intimate violence had never married (39\%), while $23 \%$ were divorced, and $23 \%$ were separated. About $1 \%$ of the female victims of intimate violence were widowed, while the remaining $14 \%$ were married.

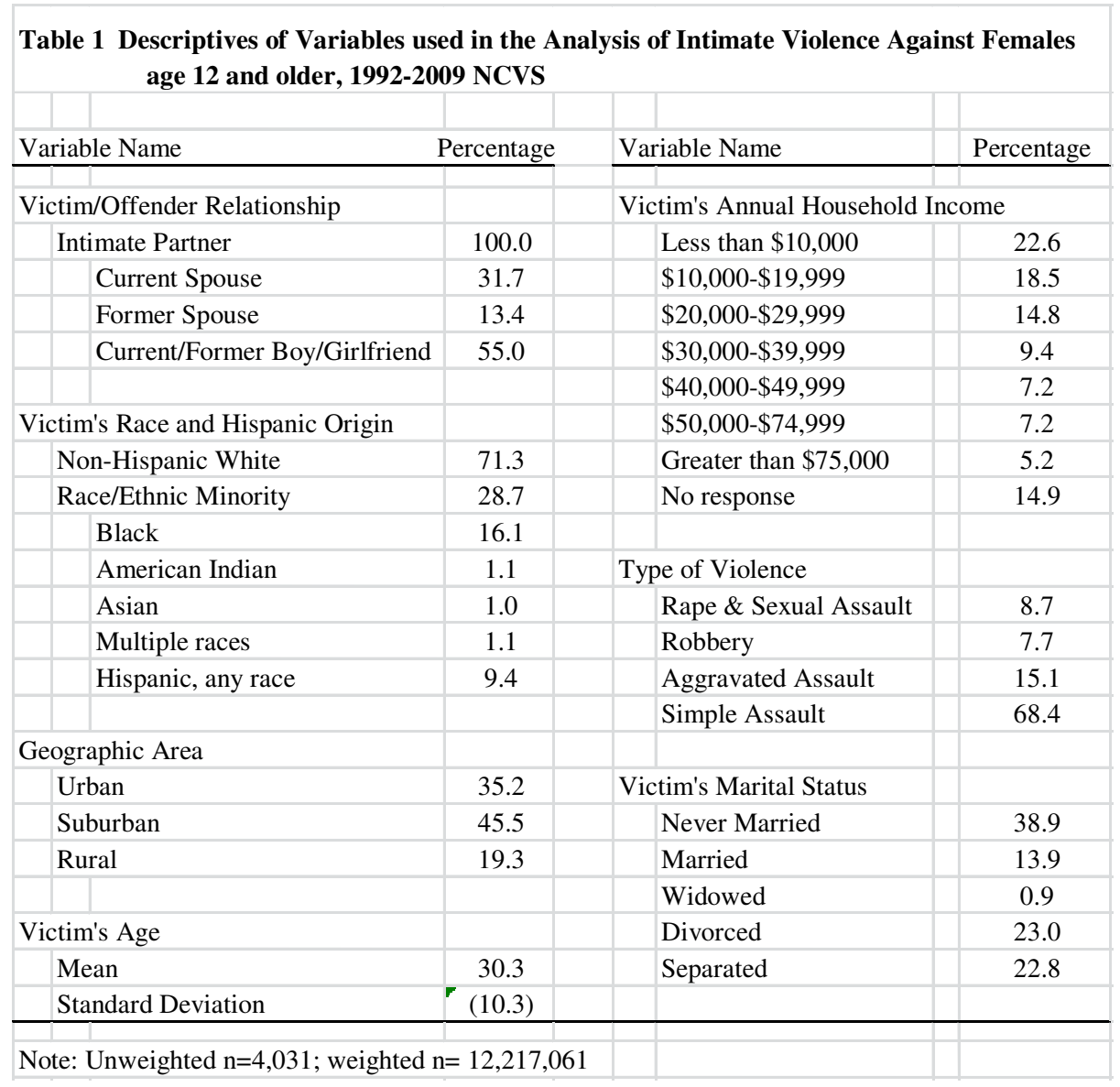

We hypothesized that rural racial/ethnic minority women would be victims of non-fatal intimate violence at rates greater than such women in urban and suburban areas. Table 2 shows rates per 1,000 for non-fatal intimate violence for female victims by race/ethnicity and geographic area. ${ }^{8}$ No support was found for the hypothesis when intimate partner was aggregated to include current and former spouses, boyfriends, and girlfriends. In fact, no statistical difference was measured between the victimization rates of rural race/ethnic minority females and their urban and suburban counterparts. One significant difference did emerge however. Findings demonstrate that urban racial/ethnic minority females are victims 
Racial/Ethnic Variations in Violence Against Women: Urban, Suburban, and Rural Differences DeKeseredy, Dragiewicz, and Rennison

of intimate violence at rates significantly greater than their suburban counterparts ( 7.4 and 5.0 , per $1,000, \mathrm{p}<.05)$. In sum, the hypothesis was not supported as rural females are victims of intimate violence at rates statistically equivalent to their urban and suburban counterparts. ${ }^{9}$

The first hypothesis test used an aggregated intimate partner measure. While informative, this approach may mask important differences found among the categories of intimate partner. A second way of testing this hypothesis is to utilize a disaggregated measure of intimate partner. That is, measuring intimate violence in three categories (current spouse, former spouse, and current/former boyfriend or girlfriend). As demonstrated in Table 2, none of these differences offered support for the hypothesis that racial/ethnic minority females in rural areas are victimized at rates greater than their counterparts in urban and suburban areas. Turning first to current spouses, findings indicate that rural racial/ethnic minority females are not victims of intimate violence at rates statistically greater than urban and suburban females. Though nominally higher, the 2.1 per 1,000 rate of intimate violence that characterizes rural racial/ethnic minority females is statistically equivalent to their urban and suburban counterparts.

\begin{tabular}{|c|c|c|c|c|}
\hline \multicolumn{5}{|c|}{$\begin{array}{r}\text { Table } 2 \text { Estimated Intimate Partner Victimization Rates per } \\
\text { Females, by Victim's Race/Hispanic Origin, and } \\
\text { Geographic Area, 1992-2009 NCVS }\end{array}$} \\
\hline & \multicolumn{4}{|c|}{ Total Intimates } \\
\hline & Urban & Suburban & Rural & Total \\
\hline Total & 7.1 & 5.4 & 6.1 & 6.1 \\
\hline White & 6.9 & 5.6 & 6.1 & 6.0 \\
\hline Racial/Ethnic Minority & 7.4 & 5.0 & 6.1 & 6.3 \\
\hline
\end{tabular}

Next, as Table 3 indicates, an examination of victimization by former spouses indicates the same outcome: Racial/ethnic minority females in rural areas are victims of intimate violence at rates statistically equivalent to urban and suburban racial/ethnic minority females. The single significant difference to emerge indicates that urban racial/ethnic minority females are victims of intimate violence at rates greater than similarly situated suburban females $(0.8$ and 0.5 per $1,000, \mathrm{p}<.05)$. Still, the hypothesis that racial/ethnic minority women in rural areas are victimized at greater rates is not supported among women victimized by former spouses. Once sampling error is accounted for, the nominal difference between rural and suburban race/ethnic minority females does not rise to the level of statistical significance.

Finally, as shown in Table 3, consideration of current and former boyfriends and girlfriends offers no support for the hypothesis. In fact, urban racial/ethnic minority females are victims of intimate violence at a rate of 5.1 per 1,000, which is significantly greater than similar suburban females $(3.0$ per 1,000$)$ and rural females $(3.1$ per $1,000, \mathrm{p}<.05)$. No difference was found between suburban and rural racial/ethnic minority females. ${ }^{10}$ 


\begin{tabular}{|c|c|c|c|c|}
\hline \multicolumn{5}{|c|}{$\begin{array}{l}\text { Females, by Victim's Race/Hispanic origin, and Geographic } \\
\text { Area, 1992-2009 NCVS }\end{array}$} \\
\hline & \multicolumn{4}{|c|}{ Current Spouses } \\
\hline & Urban & Suburban & Rural & Total \\
\hline Total & 1.8 & 1.9 & 2.1 & 1.9 \\
\hline White & 2.0 & 2.1 & 2.1 & 2.1 \\
\hline Racial/Ethnic Minority & 1.5 & 1.5 & 2.1 & 1.6 \\
\hline & \multicolumn{4}{|c|}{ Former Spouses } \\
\hline & Urban & Suburban & Rural & Total \\
\hline Total & 0.9 & 0.8 & 0.9 & 0.8 \\
\hline White & 1.0 & 0.8 & 0.9 & 0.9 \\
\hline Racial/Ethnic Minority & 0.8 & 0.5 & 0.8 & 0.7 \\
\hline & \multicolumn{4}{|c|}{ Current \& Former Boy/Girlfriends } \\
\hline & Urban & Suburban & Rural & Total \\
\hline Total & 4.4 & 2.8 & 3.1 & 3.3 \\
\hline White & 3.9 & 2.7 & 3.1 & 3.1 \\
\hline Racial/Ethnic Minority & 5.1 & 3.0 & 3.1 & 4.0 \\
\hline
\end{tabular}

A third way of testing our hypothesis is to disaggregate the results by racial and ethnic minority categories. Various groups have been found to have divergent rates of intimate violence (see e.g., Tjaden \& Thoennes 2000; Rennison \& Welchans 2000). Given this, aggregation of these groups may obscure important differences within the broader category. Accordingly, this section tests the hypothesis that racial/ethnic minority females in rural areas are victims of intimate violence at rates greater than white females, with groups disaggregated by black, American Indian, Asian, multiple race, and Hispanic females.

As shown in Table 4, and turning first to violence committed by a current spouse, two differences in support of the hypothesis were found. Specifically, rural females of multiple races are victims of intimate violence at rates significantly greater than similar females in both urban and suburban settings (25.7, 6.0 and 4.0 per 1,000 respectively, $\mathrm{p}<.05) .{ }^{11}$ A second difference was measured though it failed to support the hypothesis. Specifically, suburban Asian females are victims of intimate violence by a current spouse at rates significantly greater than rural Asian females (0.7 and 0.0 per 1,000, $\mathrm{p}<.05)$. While significant, the 0.0 rate was based on no cases of Asian rural female victims so this finding should be taken with caution. Significance testing failed to reveal any differences in victimization estimates among black, American Indian or Hispanic females. 
Racial/Ethnic Variations in Violence Against Women: Urban, Suburban, and Rural Differences DeKeseredy, Dragiewicz, and Rennison

As table 4 shows, an examination of former spouses demonstrates no support for our hypothesis that rural racial/ethnic minority females are victims of intimate violence at rates higher than urban and suburban females. In fact, the single significant difference measured was in opposition to our hypothesis. Specifically, Hispanic urban females are victims of intimate violence at rates higher than suburban and rural Hispanics. Further testing demonstrated no statistical difference in rates of intimate violence by former partners among white, black, American Indian, multiple race, or Asian females.

Finally, consideration of violence committed by current and former boyfriends and girlfriends failed to offer support of our hypothesis for the specific racial/ethnic minority groups. Similar to previous tests, no statistical difference in rates of intimate violence by current or former boyfriends and girlfriends were found among white, black, American Indian, Asian, or Hispanic females. The single difference to emerge ran counter to the hypothesis in that suburban females of multiple races were victims of intimate violence at rates higher than their rural counterparts ( 8.7 and 2.9 per $1,000, \mathrm{p}<.05)$.

\section{Conclusion}

The U.S. is a multicultural society and its composition was shaped by Aboriginal or Native American people as well as by waves of immigration. Certainly, to adequately understand violence against women in the U.S, it is essential to examine the experiences of women of different ethnic/cultural backgrounds and to place them at the center of social scientific analyses rather than delegate them to the margins (Fong 2010; Sokoloff 2005). While the literature on violence against racial/ethnic minority women is no longer scarce, there is still much we do not know, including whether such violence varies across urban, suburban, and rural areas. This study constitutes a first step toward filling this research gap.

Combined into one category, the racial/ethnic minority women examined in this study are not at greater risk of being abused in urban, suburban, or rural areas. However, it is important to recognize that these tests did not control for other important correlates of intimate victimization such as personal income, family structure, and neighborhood disadvantage (see e.g., Lauritsen \& Schaum 2004; Rennison \& Planty 2003). Failure to account for these and other characteristics may have resulted in our inability to uncover a consistent relationship between racial/ethnic characteristics and intimate victimization across geographic areas.

Additional insight was gained by disaggregating our measure of intimate partner into three relationship categories. When examining current spouses as offenders, some support for our hypothesis emerged. Rural multiple race females were victims of intimate violence at rates significantly greater than both urban and rural multiple race females $(25.7,6.0$ and 4.0 per 1,000 respectively, $\mathrm{p}<.05$ ). This finding begs further research in order to understand why 
International Journal of Rural Criminology, Volume 1, Issue 2 (November), 2012

\begin{tabular}{|c|c|c|c|c|}
\hline \multicolumn{5}{|c|}{$\begin{array}{c}\text { Table } 4 \text { Detailed Estimated Intimate Partner Victimization Rates per } \\
\text { 1,000 Females, by Expanded Victim's Race/Hispanic } \\
\text { Origin, and Geographic Area, 1992-2009 NCVS }\end{array}$} \\
\hline & \multirow{2}{*}{\multicolumn{4}{|c|}{ Current Spouses }} \\
\hline & & & & \\
\hline & Urban & Suburban & Rural & Total \\
\hline Total & 1.8 & 1.9 & 2.1 & 1.9 \\
\hline White & 2.0 & 2.1 & 2.1 & 2.1 \\
\hline Non-White & 1.5 & 1.5 & 2.1 & 1.6 \\
\hline Black & 1.5 & 1.4 & 1.1 & 1.4 \\
\hline American Indian & 1.1 & 5.4 & 5.8 & 4.6 \\
\hline Asian & 0.1 & 0.7 & --- & 0.4 \\
\hline Multiple Race & 6.0 & 4.0 & 25.7 & 8.5 \\
\hline Hispanic, any Race & 1.9 & 1.7 & 1.7 & 1.8 \\
\hline & \multirow{2}{*}{\multicolumn{4}{|c|}{ Former Spouses }} \\
\hline & & & & \\
\hline & Urban & Suburban & Rural & Total \\
\hline Total & 0.9 & 0.8 & 0.9 & 0.8 \\
\hline White & 1.0 & 0.8 & 0.9 & 0.9 \\
\hline Non-White & 0.8 & 0.5 & 0.8 & 0.7 \\
\hline Black & 0.7 & 0.6 & 0.6 & 0.6 \\
\hline American Indian & --- & 1.3 & 0.7 & 0.7 \\
\hline Asian & 0.1 & 0.3 & 1.9 & 0.2 \\
\hline Multiple Race & 1.1 & --- & --- & 0.4 \\
\hline \multirow[t]{2}{*}{ Hispanic, any Race } & 1.2 & 0.4 & 1.2 & 0.8 \\
\hline & & & & \\
\hline & \multicolumn{4}{|c|}{ Current \& Former Boy/Girlfriends } \\
\hline $\mid$ & Urban & Suburban & Rural & Total \\
\hline Total & 4.4 & 2.8 & 3.1 & 3.3 \\
\hline White & 3.9 & 2.7 & 3.1 & 3.1 \\
\hline Non-White & 5.1 & 3.0 & 3.1 & 4.0 \\
\hline Black & 7.1 & 5.0 & 2.7 & 5.8 \\
\hline American Indian & 19.0 & 6.9 & 5.0 & 8.7 \\
\hline Asian & 1.2 & 0.9 & --- & 1.0 \\
\hline Multiple Race & 18.8 & 8.7 & 2.9 & 11.0 \\
\hline Hispanic, any Race & 3.1 & 1.9 & 3.8 & 2.6 \\
\hline --- indicates insufficient s & ize for & iable estin & & \\
\hline
\end{tabular}


Racial/Ethnic Variations in Violence Against Women: Urban, Suburban, and Rural Differences DeKeseredy, Dragiewicz, and Rennison

these rates in particular were so high. While the high victimization rate for multiple race rural females offers support for our hypothesis, none was found when considering other racial/ethnic minorities in the current spouse category. Nor was support found for greater rural victimization by former spouses or current and former boyfriends or girlfriends. While disaggregation offered information about variation within the broader racial and ethnic minority category, it also led to a significant reduction in cell sample size. That many cells were based on few cases of intimate violence (especially for racial/ethnic minorities in rural areas), meant the loss of important statistical power needed to identify relationships between geographic areas and intimate violence within groups. More data are needed to better understand this issue. Qualitative research will also be needed to improve our understanding of these issues in areas with small sample sizes for racial/ethnic minority women.

As is often said, more research needs to be done. For example, the criticisms of examining pan-ethnic categories described earlier need to be taken seriously. Moreover, the plight of immigrant and refugee women warrants additional scrutiny because their experiences are not adequately addressed in large national samples. These women are often classified as "white," obscuring issues related to ethnicity and immigration status. Related to these problems is that some common types of abuse directed at immigrant and refugee women, such as using immigration status as a method of coercive control, are not measured in mainstream surveys or by widely used violence measures such as Straus, Hamby, BoneyMcCoy \& Sugarman's (1996) revised Conflict Tactics Scale (CTS) (Dutton, Orloff \& Hass 2000; Perilla et al. 2011). Likewise, national studies may mask important local factors determining victimization rates, pointing to the need for community-specific studies.

There are, of course, a growing number of qualitative and quantitative studies of the abuse of Native or Indian women in rural communities. However, the plight of rural women belonging to other ethnic/minority groups has thus far received short shrift. Certainly, the bulk of the empirical and theoretical work on woman abuse in rural parts of the U.S. focuses almost exclusively on white women, especially those living in Appalachia (e.g., DeKeseredy \& Schwartz 2009; Websdale 1998). Are ethnic/minority women's needs and experiences similar to or different than those of white women? This is an empirical question that can only be answered empirically and hopefully answers will be provided by the rural criminological community in the near future.

In addition to designing samples, quantitative measures, and qualitative studies that effectively address the multicultural nature of the U.S., there is a great need for theoretically driven research, especially on sexual assaults against ethnic/minority women (Ullman \& Najdowski 2011). And, of course, it is important to constantly avoid stereotyping or constructing perpetrators of violence against ethnic/minority women as "Others." As Aronson Fontes and McCloskey remind us, "there are few forms of violence that belong exclusively to any particular culture" (2011, p. 152). Indeed, our preliminary findings suggest that the ubiquity of patriarchy may be more important than in shaping violence against women than rural, suburban, or urban location. 


\section{Endnotes}

1. Though 1992 represents a point at which major methodological changes were implemented in the survey, changes are made on an ongoing basis. In 2006, several changes were made including the elimination of centralized CATI, using a large proportion of new interviewers, a reduction in sample size, and the inclusion of unbounded surveys in the NCVS. In addition, a change that modified the sampling frame was introduced. This change had an extreme effect on 2006 estimates that were due to methodology and not changes in victimization or sampling variation (Truman \& Rand, 2010). Further it was found that the greatest problems were centered in rural areas. In 2007, these detrimental changes were terminated, making the data from 2007 on appropriate for use. Because the problems are confined only to 2006 data, these are excluded from the present analyses.

2. For example, between 1993 and 1999, 2\% of intimate violence against women was committed by a female and $10 \%$ of intimate violence against men was committed by a male (Rennison et al., in press a).

3. The precise measure used is V2129 in the NCVS data. The value labels provided in the data are "city of (S)MSA", "(S)MSA not city" and "Not (S)MSA. As noted in the text, we use "urban," "suburban" and "rural" in lieu of the provided labels. This is consistent with a wide variety of publications making use of the particular variable.

4. Many scholars have outlined the limitations of the NCVS as a measure of non-lethal violence against women. See for example Bachman 2000 and DeKeseredy 2000.

5. The "multiple race" category became available in the NCVS in 2003.

6. See Rennison et al. (in press a) for a more detailed account of the advantages and disadvantages of using the NCVS to compare variation in violence against women.

7. For more information on NCVS weighting procedures or the NCVS in general, see Rennison and Rand (2007).

8. Confidence intervals for all estimates presented are available upon request.

9. Though not the focus of this hypothesis test, findings show differences in estimates within geographic area. The first difference detected is that racial/ethnic minority females are victims of intimate violence at rates significantly greater than white females in urban areas ( 7.4 and 6.9 per $1,000, p<.05)$. Findings are the opposite in suburban areas where findings indicate that white females are victimized by an intimate at rates significantly greater than racial/ethnic minorities (5.6 and 5.0 intimate victimizations per 1,000, p<.05). In rural areas, white and racial/ethnic minorities are victims of intimate violence at statistically equal rates (6.1 per 1,000 each). 
Racial/Ethnic Variations in Violence Against Women: Urban, Suburban, and Rural Differences DeKeseredy, Dragiewicz, and Rennison

10. Findings reveal that racial/ethnic minority rural females were victims of intimate violence at rates statistically equivalent to white rural females for all three categories of intimate partner: Current spouses, former spouses, and current/former boyfriends and girlfriends.

11. The finding regarding rural females of multiple races having significantly higher rates of IPV than their urban and suburban counterparts is especially noteworthy as this racial category was not available in the NCVS until 2003. Had these females had the opportunity to correctly place themselves into a "multiple race" category in prior years, greater differences may have been measured in this particular test as well as others. 
International Journal of Rural Criminology, Volume 1, Issue 2 (November), 2012

\section{Acknowledgements}

The authors would like to thank Joseph Donnermeyer, Claire Renzetti, and Martin D. Schwartz for their assistance. Please send all correspondence to Walter DeKeseredy. 
Racial/Ethnic Variations in Violence Against Women: Urban, Suburban, and Rural Differences DeKeseredy, Dragiewicz, and Rennison

\section{References}

Addington, L. \& C. Rennison. 2008. Rape co-occurrence: Do additional crimes affect victim reporting and police clearance of rape? Journal of Quantitative Criminology 24, 205 226.

Aldarondo, E. \& M. Castro-Fernandez. 2011. Risk and protective factors for intimate partner violence'. In J.W. White, M.P. Koss \& A.E. Kazdin (eds.), Violence Against Women and Children. Washington, DC: American Psychological Association.

Aldarondo, E. \& M. Castro-Fernandez. 2008. Intimate partner violence and recidivism following interventions with men who batter: Cultural and empirical considerations'. In R. Carillo \& J. Tello (eds.), Family Violence and Men of Color: Healing the Wounded Male Spirit. New York: Springer.

Aldarondo, E., G.K. Kaufman Kantor, \& J.L. Jasinski. 2002. A risk marker analysis for wife assault in Latino families. Violence Against Women 8, 429-454.

Fontes, L.A. \& K.A. McCloskey. 2011. Cultural issues in violence against women. In C.M. Renzetti, J.L. Edleson \& R. Kennedy Bergen (eds.), Sourcebook on Violence Against Women. Thousand Oaks, CA: Sage.

Bachman, R. 2000. A comparison of annual incidence rates and contextual characteristics of intimate-partner violence against women from the national crime victimization survey (NCVS) and the national violence against women survey (NVAWS). Violence Against Women 6, 839-867.

Basile, K.C. \& M.C. Black. 2011. Intimate partner violence against women. In C.M. Renzetti, J.L. Edleson \& R. Kennedy Bergen (eds.), Sourcebook on Violence Against Women. Thousand Oaks, CA: Sage.

Breiding, M., J.S. Ziembroski, \& M.C. Black. 2009. Prevalence of rural intimate partner violence in 16 states, 2005. Journal of Rural Health 25, 240-246.

Brownridge, D.A. 2009. Violence Against Women: Vulnerable Populations. New York, NY: Routledge.

Chakraborti, N. \& J. Garland. (Eds.). 2004. Rural Racism. Portland, OR: Willan.

Cloke, P. 2004. Rurality and racialised others: Out of place in the countryside? In N. Chakraborti \& J. Garland (eds.), Rural Racism. Portland, OR: Willan.

DeKeseredy, W.S. 1990. Male peer support and woman abuse: The current state of knowledge. Sociological Focus 23, 129-139. 
DeKeseredy, W.S. 2000. Current controversies on defining non-lethal violence against women in intimate heterosexual relationships: Empirical implications. Violence Against Women 6, 32-50.

DeKeseredy, W.S. \& M.D. Schwartz. 2008. Separation/divorce sexual assault in rural Ohio: Survivors' perceptions. Journal of Prevention and Intervention in the Community 36, 105-120.

DeKeseredy, W.S. \& M.D. Schwartz. 2009. Dangerous Exits: Escaping Abusive Relationships in Rural America. New Brunswick, NJ: Rutgers University Press.

Duhart, D.T. 2000. Urban, Suburban and Rural Victimization, 1993-98. Washington, DC: Bureau of Justice Statistics.

Dutton, M.A., L. Orloff, \& G.A. Hass. 2000. Characteristics of help-seeking behaviors, resources and services seeds of battered immigrant Latinas: Legal and policy implications. Georgetown Journal on Poverty Law and Policy 7, 247-305.

Fong, J. 2010. Introduction. In J. Fong (ed.), Out of the Shadows: Woman Abuse in Ethnic, Immigrant and Aboriginal Communities. Toronto: Women's Press.

Hogg, R. and C. Carrington. 2006. Policing the Rural Crisis. Sydney, AU: The Federation Press.

Hubble, D.L. 1995. The national crime victimization survey redesign: New questionnaire and procedures development and phase-in methodology. Paper presented at the annual meetings of the American Statistical Association, Orlando, Florida. August.

Kaufman Kantor, G., J.L. Jasinski, \& E. Aldarondo. 1994. Sociocultural status and incidence of violence against women in Hispanic families. Violence and Victims. 9, 207-222.

Kindermann, C., J. P. Lynch, \& D. Cantor. 1997. The Effects of the Redesign on Victimization Estimates (NCJ-164381). Washington, DC: U.S. Department of Justice.

Lauritsen, J.L. \& K. Heimer. 2008. The gender gap in violent victimization, 1973-2004. Journal of Quantitative Criminology 24, 125-147.

Lauritsen, J.L. \& R.J. Schaum. 2004. The social ecology of violence against women. Criminology 42, 323-357.

Lewis, S.H. 2003. Unspoken Crimes: Sexual Assault in Rural America. Enola, PA: National Sexual Violence Resource Center.

Logan, T.K., J. Cole, L. Shannon, \& R. Walker. 2006. Partner Stalking: How Women Respond, Cope and Survive. New York, NY: Springer. 
Racial/Ethnic Variations in Violence Against Women: Urban, Suburban, and Rural Differences DeKeseredy, Dragiewicz, and Rennison

Logan, T.K., L. Evans, E. Stevenson, \& C.E. Jordan. 2005. Barriers to services for rural and urban survivors of rape. Journal of Interpersonal Violence 20, 591-616.

Meloy, M.L. \& S.L. Miller. 2011 . The Victimization of Women: Law, Policies and Politics. New York: Oxford University Press.

Mueller, K.J. \& A.C. MacKinney. 2006. Care across the continuum: Access to health care services in rural America. Journal of Rural Health 22, 43-49.

Patterson, P.D. 2006. Emergency medical services and the federal government's evolving role: What rural and frontier emergency medical services advocates should know. Journal of Rural Health 22, 97-101.

Perilla, J.L., C. Lippy, A. Rosales, \& J.V. Serrata. 2011. Prevalence of domestic violence. In J.W. White, M.P. Koss and A.E. Kazdin (eds.), Violence Against Women and Children, Washington, DC: American Psychological Association.

Potter, H. 2008. Battle Cries: Black Women and Intimate Partner Violence. New York: New York University Press.

Rand, M. R., J.P. Lynch, \& D. Cantor. 1997. Criminal Victimization 1973-95 (NCJ163069). Washington, DC: U.S. Department of Justice.

Rennison, C.M. \& M. Rand. 2003. Criminal Victimization 2002. Washington, DC, United States Government Printing Office.

Rennison, C.M. 2002. Criminal Victimization 2001: Changes 2000-2001 with Trends 19932001. Washington, DC, United States Government Printing Office.

Rennison, C.M. 2001. Criminal Victimization 2000: Changes 1999-2000 with Trends 19932000. Washington, DC, United States Government Printing Office.

Rennison, C.M. 2000. Criminal Victimization 1999: Changes 1998-1999 with Trends 19931999. Washington, DC, United States Government Printing Office.

Rennison, C.M. 1999. Criminal Victimization 1998: Changes 1997-1998 with Trends 19931998. Washington, DC, United States Government Printing Office.

Rennison, C.M., W.S. DeKeseredy, and M. Dragiewicz. In press a. Intimate relationship status variations in violence against women: Urban, suburban and rural differences. Violence Against Women.

Rennison, C.M., W.S. DeKeseredy, \& M. Dragiewicz. In press b. Urban, suburban and rural variations in separation/divorce rape/sexual assault'. Feminist Criminology. 
Rennison, C.M., M., Dragiewicz, \& W.S. DeKeseredy. In press. Context Matters: Violence against women and reporting to police in rural, suburban and urban areas. American Journal of Criminal Justice.

Rennison, C.M. \& M. Planty. 2003. Nonlethal intimate partner violence: Examining race, gender and income patterns. Violence and Victims, 18: 433-443.

Rennison, C.M. \& M. Rand. 2007. Introduction to the National Crime Victimization Survey. In J. P. Lynch and L. A. Addington (eds.), Understanding Crime Statistics: Revisiting the Divergence of the NCVS and the UCR. New York, NY: Cambridge University Press.

Renzetti, C.M., J.L. Edleson, \& R. Kennedy Bergen. 2011. Preface. In C.M. Renzetti, J.L. Edleson and R. Kennedy Bergen (eds.), Sourcebook on Violence Against Women. Thousand Oaks, CA: Sage.

Richie, B.E. 2005 . Foreword. In N. Sokoloff (ed.), Domestic violence at the margins: Readings on Race, Class, Gender and Culture. New Brunswick, NJ: Rutgers University Press.

Sokoloff, N.J. (ed.). 2005. Domestic Violence at the Margins: Readings on Race, Class, Gender and Culture. New Brunswick, NJ: Rutgers University Press.

Stanko, E.A. 1985. Intimate intrusions: Women's Experience of Male Violence. London: Routledge and Kegan Paul.

Straus, M.A., S.L. Hamby, S. Boney-McCoy, \& D.B. Sugarman. 1996. The revised Conflict Tactics Scales (CTS): Development and preliminary psychometric data. Journal of Family Issues, 17, 283-316.

Tjaden, P. \& N. Thoennes. 2000. Extent, Nature and Consequences of Intimate Partner Violence: Findings from the National Violence Against Women Survey. Washington, DC: National Institute of Justice.

Truman, J.L. \& M. Rand. 2010. Criminal Victimization 2009. Washington, DC: USGPO.

Ullman, S.E. \& C. Najdowski. 2011. Vulnerability and protective factors for sexual assault. In J.W. White, M.P. Koss and A.E. Kazdin (eds.), Violence Against Women and Children. Washington, DC: American Psychological Association.

Websdale, N. 1998. Rural Woman Battering and the Justice System: An Ethnography. Thousand Oaks, CA: Sage.

Websdale, N. \& B. Johnson. 2005. Reducing woman battering: The role of structural approaches. In N. Sokoloff (ed.), Domestic violence at the margins: Readings on race, class, gender and culture. New Brunswick, NJ: Rutgers University Press. 